\title{
Use of a buccinator myomucosal flap and bilateral pedicled buccal fat pad transfer in wide palatal fistula repair: a case report
}

Jin Mi Choi,

Hojin Park,

Tae Suk Oh

Department of Plastic and

Reconstructive Surgery, Asan Medical

Center, University of Ulsan College of

Medicine, Seoul, Korea

\begin{abstract}
Primary palatoplasty for cleft palate places patients at high risk for scarring, altered vascularity, and persistent tension. Palatal fistulas are a challenging complication of primary palatoplasty that typically form around the hard palate-soft palate junction. Repairing palatal fistulas, particularly wide fistulas, is extremely difficult because there are not many choices for closure. However, a few techniques are commonly used to close the remaining fistula after primary palatoplasty. Herein, we report the revision of a palatal fistula using a pedicled buccal fat pad and palatal lengthening with a buccinator myomucosal flap and sphincter pharyngoplasty to treat a patient with a wide palatal fistula. Tension-free closure of the palatal fistula was achieved, as well as velopharyngeal insufficiency (VPI) correction. This surgical method enhanced healing, minimized palatal contracture and shortening, and reduced the risk of infection. The palate healed with mucosalization at 2 weeks, and no complications were noted after 4 years of follow-up. Therefore, these flaps should be considered as an option for closure of large oronasal fistulas and VPI correction in young patients with wide palatal defects and VPI.
\end{abstract}

Abbreviations: BFP, buccal fat pad; ONF, oronasal fistula; VPI, velopharyngeal insufficiency.

Keywords: Cleft palate / Oral fistula / Reconstructive surgical procedures / Velopharyngeal insufficiency

\section{INTRODUCTION}

In primary palatoplasty, anatomically oriented, tension-free, atraumatic complete closure is the key in achieving normal speech after a sufficient velopharyngeal closure and in preventing postoperative fistula development. Palatal fistulas are a challenging complication of primary palatoplasty that typically form around the hard palate-soft palate junction. The shortage of local tissues creates significant tension during closure, thus

Correspondence: Tae Suk Oh

Department of Plastic and Reconstructive Surgery, Asan Medical Center,

University of Ulsan College of Medicine, 88 Olympic-ro 43-gil, Songpa-gu, Seoul 05505, Korea

E-mail: tasuko@amc.seoul.kr

Received July 2, 2021 / Revised July 29, 2021 / Accepted August 20, 2021 increasing the risk of an oronasal fistula (ONF). Repairing palatal fistulas, particularly wide fistulas, is extremely difficult because the options for closure are limited. However, a few techniques are commonly used to close the remaining fistula after primary palatoplasty. Herein, we report the revision of a palatal fistula using a pedicled buccal fat pad (BFP), palatal lengthening with a buccinator myomucosal flap and sphincter pharyngoplasty to treat a patient with a wide palatal fistula. Tensionfree closure of the palatal fistula was achieved along with correction of velopharyngeal insufficiency (VPI). This surgical method enhanced healing, minimized palatal contracture and shortening, and reduced the risk of infection. The palate healed with mucosalization after 2 weeks, and no complications were noted after 4 years of follow-up. Therefore, these flaps can be 
considered as an option for closure of large ONFs and VPI correction in young patients with wide palatal defects and VPI.

\section{CASE REPORT}

\section{Diagnosis and treatment plan}

A 5-year-old boy with cleft lip and palate was referred for a wide palatal defect. The patient had undergone pharyngeal flap surgery for ONF closure at another institution. However, the posterior pharyngeal flap was lost entirely, and a wide V-shaped defect was noticed on his hard and soft palate (Fig. 1). Additionally, the patient presented with severe VPI. Speech analysis showed severe hypernasality and compensatory errors were present with a glottal stop. Therefore, a surgical intervention was required for defect closure and hypernasality relief. A free flap, such as a radial forearm free flap, would have been indicated due to the severity of the defect and the presence of fibrotic tissue surrounding the defect. However, because of the patient's age and concerns of donor-site morbidity, local tissue transfer

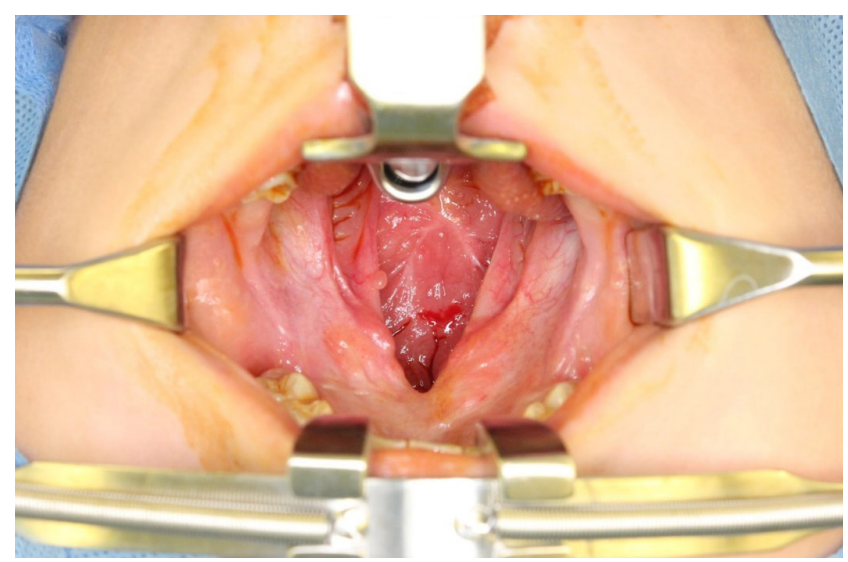

Fig. 1. A 5-year-old boy with wide palatal fistula and velopharyngeal insufficiency after primary palatoplasty.

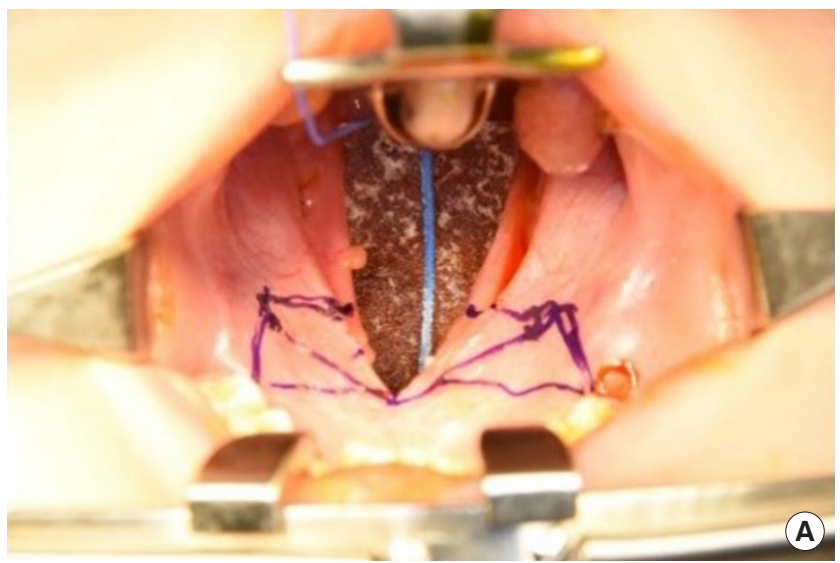

was chosen instead of free tissue transfer [1]. Therefore, we planned for a pedicled BFP flap and palatal lengthening with a buccinator myomucosal flap, as well as superior-based sphincter pharyngoplasty for VPI correction

\section{Treatment process}

The patient presented with a severe palatal scar and surrounding fibrous tissue. The hard and soft palate were both thin, and there was no uvula. The patient underwent four operations. The first operation aimed to restore the levator sling and the palatal musculature. The second operation aimed at defect closure using bilateral pedicled buccal flaps. During the third procedure repair was attempted with a buccinator myomucosal flap. The final operation achieved closure using a superiorbased pharyngeal flap. The width of the cleft palate was measured intraoperatively as approximately $16 \mathrm{~mm}$. An incision was made along the soft palate margin, starting from the hard palate-soft palate junction. The levator was then detached from the soft palate, the muscles were reoriented, and the palatopharyngeus muscle was repaired.

After the first palatal repair, the wound margin showed dehiscence, the fistula remained present, and the VPI did not improve. The palatal defect was subsequently measured as $8 \mathrm{~mm}$. Follow-up speech analysis showed severe hypernasality. Therefore, a bilateral pedicled BFP flap was planned. A rectangular mucosal flap, the base of which was at the defect margin, was elevated to repair the nasal-side defects (Fig. 2). A bilateral BFP flap was used to cover the oral-side defects.

After the second operation, the BFP flaps were successfully replaced with granulation tissue and mucosa (Fig. 3). The patient's hypernasality was graded as moderate to severe. After 3 months of follow-up, flap volume had substantially decreased and his pronunciation had not improved. Therefore, we planned palatal lengthening using a buccinator myomucosal

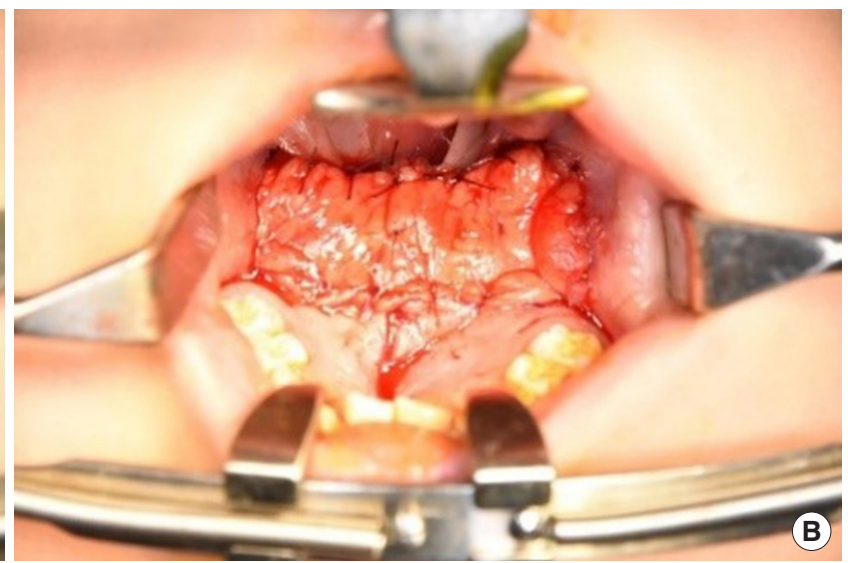

Fig. 2. (A) Incision design for a bilateral buccal fat pad flap. (B) Immediate postoperative photograph. 


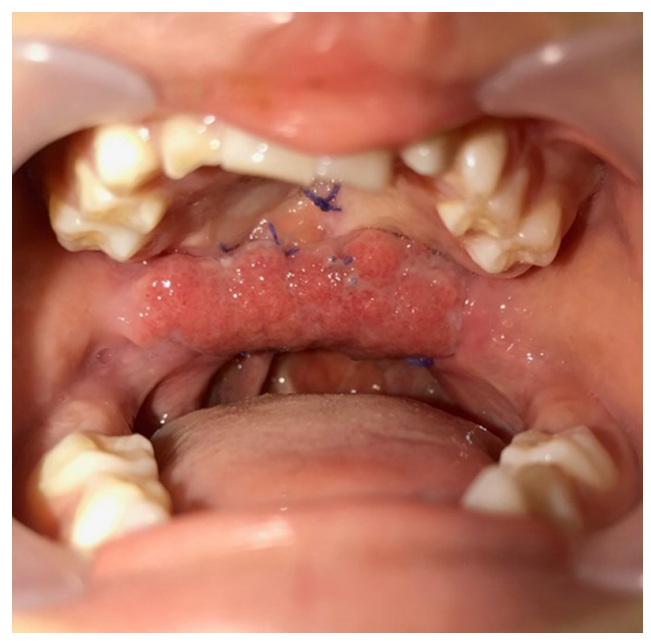

Fig. 3. Successfully replaced buccal fat pad flaps after the second operation.



Fig. 4. (A) Incision design for a buccinator myomucosal flap. (B) Immediate postoperative photograph.

flap. At the time of the third operation, the soft palate was short, and the distance from the uvula to the pharyngeal wall was 16 $\mathrm{mm}$. An incision was made on the buccal mucosa (Fig. 4), and buccinator myomucosal flap elevation was performed. The flap was inserted into the defect side, and the oral lining was re-

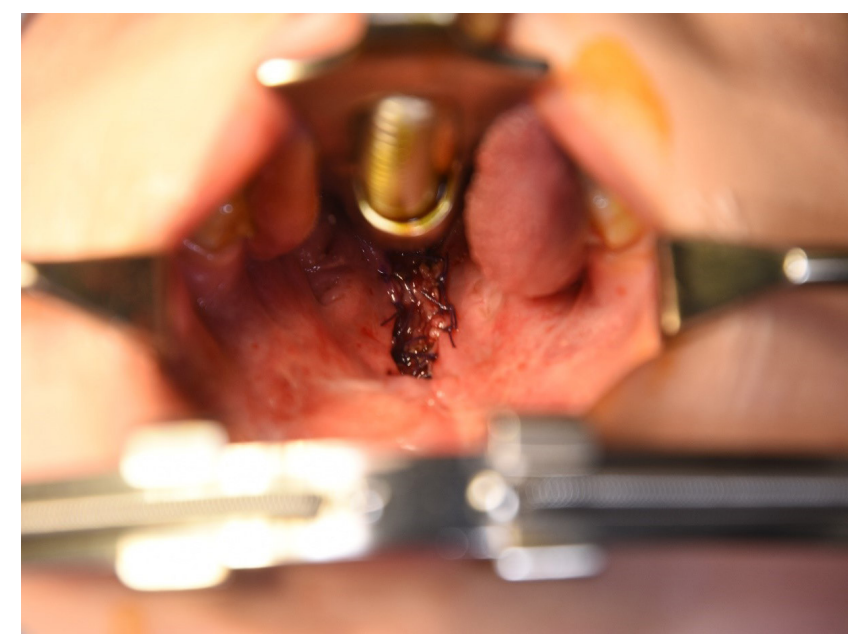

Fig. 5. Photograph taken immediately after sphincter pharyngoplasty.

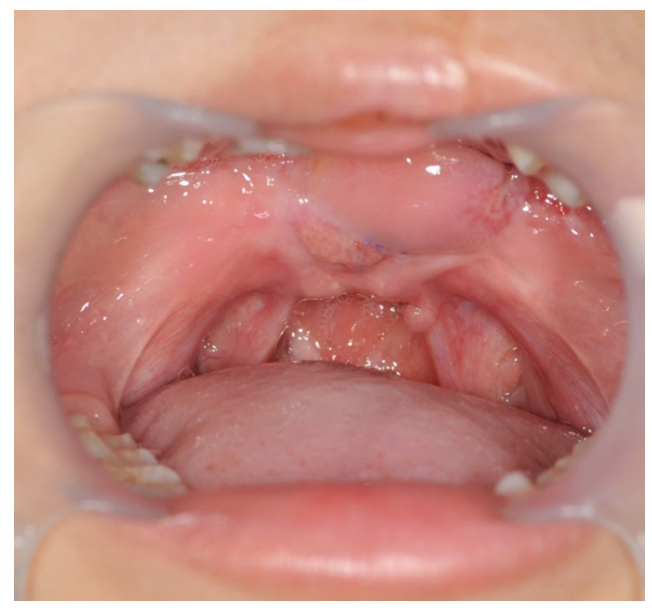

Fig. 6. Photograph 3 months after the final operation.

paired using 4-0 Vicryl. The flap pedicle remained a raw surface for future division, and the distance from the uvula to pharyngeal wall decreased from $16 \mathrm{~mm}$ to $11 \mathrm{~mm}$. After 3 weeks, division of the buccinator myomucosal flap was performed. The wound completely healed without complications.

The patient's hypernasality decreased after the third operation, but was still considered unacceptable; therefore, the patient was scheduled for sphincter pharyngoplasty. The patient's hypernasality degree was moderate to severe. Although scar tissue had formed after the previous pharyngoplasty, we successfully elevated two arms of a superior-based pharyngeal flap. The flaps were then rotated medially and inset into a transverse incision in the posterior pharyngeal mucosa (Fig. 5).

The wound healed completely, as shown in Fig. 6. Final hypernasality was graded as mild, and developmental errors decreased. 


\section{Treatment results}

The patient was 9 years old at the time of the final operation. The lengthening of the palate was well maintained (Fig. 6), and follow-up speech analyses showed significant improvements in the VPI. Hypernasality grade became mild, developmental errors decreased, and the level of articulation was moderate. Regular speech therapy was performed.

\section{DISCUSSION}

Palatal fistula is a challenging complication following cleft palate repair [2-4]. Reparative surgery is complex because of inevitable scarring, altered vascularity, and persistent tension after primary palatoplasty [5-7]. However, watertight, tension-free closure of the palate fistula remains the primary treatment of choice, especially for wide fistulas [2]. The rate of postoperative fistula formation differs according to the surgical method, but generally ranges from $2.4 \%$ to $35 \%$. Closure of large ONFs in patients with cleft palate is particularly complex for reconstructive surgeons [8,9]. Additionally, children with a wide cleft fistula commonly have reduced VPI, impaired language development, and an impacted quality of life [10]. Therefore, early correction is needed to minimize adverse outcomes. Thus far, aberrant palatal muscle attachment release and radical backward dissection remain the mainstay techniques for favorable surgical results $[5,6]$. However, a lack of local tissues creates tension during closure and places the patient at risk for an ONF. Facial artery musculomucosal flaps, submental flaps, and temporal and temporoparietal fascial flaps are reparative options. However, these require extraoral skin incisions, and there is a risk of injury to the marginal mandibular branch of the facial nerve $[8,11]$. These techniques are also exceptionally high risk for pediatric patients [8,10-13].

As described above, we performed a total of four operations to resolve the problem. Operations 1 and 2 focused on repairing the fistula (defect repair), while operations 3 and 4 focused on correcting the VPI. Using a pedicle-based buccinator myomucosal flap has the advantage of replacing the lost tissue with the same type of tissue $[8,14]$. The myomucosal buccinator flap, first described by Bozola in 1989, has become an essential tool for intraoral defect reconstruction. Various forms of myomucosal cheek flaps have been proposed in the literature, both pedicled and island, based on the buccal or the facial arteries [14]. Cases of myomucosal flaps used for tongue reconstruction have also been reported $[13,14]$. Furthermore, the use of pharyngoplasty for VPI correction is associated with favorable speech outcomes [15].

This report presents in detail the rare use of a bilateral bucci- nator myomucosal flap and pedicled BFP transfer in wide cleft palate fistula repair in a pediatric patient. The proximity of the donor site to the palatal region, obviating the need for an extraoral skin incision, and minimal donor-site morbidity are other reasons to consider this surgical technique, especially for pediatric patients $[16,17]$. Sensibility is expected to return to the flap given its neurovascular axial pattern and the fact that its blood supply comes from the buccal artery (a branch of the maxillary artery) $[16,17]$. The final speech analysis report indicated that the patient's VPI had improved extensively.

This report demonstrates a case of a wide palatal fistula wherein a tension-free, watertight closure for both the nasal and oral mucosa was not possible. Instead, the combination of a bilateral buccinator myomucosal flap and pedicled BFP transfer was a feasible and cost-effective technique. The patient required long-term follow-up to monitor his speech development and palate growth. Therefore, a posteriorly based buccinator myomucosal flap might be considered to close large ONFs and improve VPI in young patients with cleft palate.

\section{NOTES}

\section{Conflict of interest}

No potential conflict of interest relevant to this article was reported.

\section{Ethical approval}

The study was approved for exemption by the Institutional Review Board of Asan Medical Center (IRB exemption No. 20210934) and performed in accordance with the principles of the Declaration of Helsinki. Written informed consent was obtained.

\section{Patient consent}

The patient's guardian provided written informed consent for the publication and the use of patient images.

\section{ORCID}

Jin Mi Choi https://orcid.org/0000-0002-1855-7910

Hojin Park https://orcid.org/0000-0001-9809-0558

Tae Suk Oh https://orcid.org/0000-0001-8174-8915

\section{Author contribution}

Conceptualization: HP, TSO. Data curation: JMC, HP, TSO. Methodology: TSO. Visualization: HP. Writing - original draft: JMC, HP. Writing - review \& editing: JMC, HP. Supervision: TSO. 


\section{REFERENCES}

1. Jeong EC, Jung YH, Shin JY. Use of postoperative palatal obturator after total palatal reconstruction with radial forearm fasciocutaneous free flap. J Craniofac Surg 2015;26:e383-5.

2. Agir H, Eren GG, Yasar EK. Acellular dermal matrix use in cleft palate and palatal fistula repair: a potential benefit? J Craniofac Surg 2015;26:1517-22.

3. Ashtiani AK, Emami SA, Rasti M. Closure of complicated palatal fistula with facial artery musculomucosal flap. Plast Reconstr Surg 2005;116:381-6.

4. Helling ER, Dev VR, Garza J, Barone C, Nelluri P, Wang PT. Low fistula rate in palatal clefts closed with the Furlow technique using decellularized dermis. Plast Reconstr Surg 2006; 117:2361-5.

5. Bozola AR, Gasques JA, Carriquiry CE, Cardoso de Oliveira M. The buccinator musculomucosal flap: anatomic study and clinical application. Plast Reconstr Surg 1989;84:250-7.

6. Kim SK, Moon JB, Heo J, Kwon YS, Lee KC. The treatment of the large palatal fistula using the tongue flap. J Korean Cleft Palate-Craniofac Assoc 2007;8:49-53.

7. Ha JH, Jeong Y, Koo YT, Jeon S, Chung J, Kim S. Effect of collagen matrix on postoperative palatal fistula in cleft palate repair. Sci Rep 2020;10:15236.

8. Chow TL, Kwan WWY, Fung SC, Ho LI, Au KL. Reconstruction with submental flap for aggressive orofacial cancer: an up- dated series. Am J Otolaryngol 2018;39:693-7.

9. Goh BKL, Chia HL. The use of acellular dermal matrix in combination with pedicled buccal fat pad in wide cleft palate repair: a case report and literature review. Cleft Palate Craniofac J 2019;56:1381-5.

10. Sommerlad BC. A technique for cleft palate repair. Plast Reconstr Surg 2003;112:1542-8.

11. Kim SK, Kim JC, Park SS, Lee KC. One stage correction of the severe secondary cleft lip nasal deformities in foreigners. J Korean Cleft Palate-Craniofac Assoc 2011;12:102-6.

12. Rahpeyma A, Khajehahmadi S. Buccinator-based myomucosal flaps in intraoral reconstruction: a review and new classification. Natl J Maxillofac Surg 2013;4:25-32.

13. Smith DM, Losee JE. Cleft palate repair. Clin Plast Surg 2014; 41:189-210.

14. Rahpeyma A, Khajehahmadi S. Closure of huge palatal fistula in an adult patient with isolated cleft palate: a technical note. Plast Reconstr Surg Glob Open 2015;3:e306.

15. Lee YW, Bae YC, Park SM, Nam SB, Seo HJ, Kim GW. Outcomes of a superiorly-based pharyngeal flap for the correction of velopharyngeal dysfunction. Arch Craniofac Surg 2020;21: 22-6.

16. Will LA. Growth and development in patients with untreated clefts. Cleft Palate Craniofac J 2000;37:523-6.

17. Sharma S, Chauhan JS. An infant with a palatal fistula secondary to Candida infection. Arch Craniofac Surg 2020;21:206-9. 